\title{
KADIN VE ERKEKLERDE SOSYAL SERMAYE VE BENLİK KURGULARI ARASINDAKİ İLIŞKILLER
}

\author{
Mehmet Ertuğrul UÇAR ${ }^{1}$ Rezzan GÜNDOĞDU ${ }^{2}$ Ümit MORSÜNBÜL ${ }^{3}$ Bilge KONAL ${ }^{4}$
}

\section{Özet}

Bireylerin kendilerini özerk ya da ilişkisel hissetmesi, benlik kurgularıyla ilgilidir. Sosyal sermaye, güvene dayalı insan ilişkilerinin ürünüdür ve maddi olmayan bir sermaye türüdür. Sosyal sermaye; güven, ortak değerler ve iletişim ağları ile birbirine bağlanmayı içeren grup aidiyeti duygusundan oluşur. Başka insanları tanıyor olmak ve o insanlar ile iletişim halinde olmak, bir yerde, sosyal sermayenin oluşması için yeterli değildir. Bu insanlara güvenmek, kendinizi tanıdığınız insanlardan oluşan bir gruba ait hissetmek ve iletişim kurduğunuz kişilerle bazı ortak değerleri taşıdığınıza inanmak gerekir. $\mathrm{Bu}$ araştırmanın amacı, kadın ve erkeklerde ilişkisel ve özerk benlik kurgularını stratejik güven, genelleştirilmiş güven, kurumsal güven ve ortak değerlerin yordayıp yordamadığını ortaya koymaktır. Araştırma grubu 236 üniversite öğrencisinden oluşmaktadır (\%66.7 kadın, \%33.3 erkek).Verilerin analizinde Pearson Korelasyon katsayısı ve regresyon modeli kullanılmıştır. Genel olarak stratejik güven, genelleştirilmiş güven, kurumsal güven ve ortak değerler özerk ve ilişkisel benliği yordamıştır.
\end{abstract}

Anahtar Kelimeler: Sosyal Sermaye, Özerklik, İlişkisellik

\section{RELATIONSHIP BETWEEN SOCIAL CAPITAL AND SELF CONSTRUAL AT WOMEN AND MEN}

\begin{abstract}
Self construal is people felling autonomous relatedness or not. Social capital is a result of human relations that depend on trust and is a non-material capital. Social capital consists of trust, common values and the emotions of groups belongingness created by social networks. To know people and to be in touch with them is not enough for the emergence of a social capital. To feel belonged to the people that you know, to trust these people, and to believe that you are sharing common values with these people are necessary for the social capital. The aim of this study is to examine whether; strategic trust, generalized trust, institutional trust and common values, are predict autonomous, relatedness self or not at women and men. The research group consisted of $240(66.7 \%$ female, $33.3 \%$ male) university students. The preliminary analyses showed that strategic trust, generalized trust, institutional trust and common values significantly predicted autonomy; relatedness self.
\end{abstract}

Keywords: Social Capital, Autonomous, Relatedness Self

\footnotetext{
${ }^{1}$ Dr. Öğr. Üyesi, Aksaray Üniversitesi Eğitim Fakültesi Eğitim Bilimleri Bölümü, ertugrulucar@aksaray.edu.tr

${ }^{2}$ Doç. Dr., Aksaray Üniversitesi Eğitim Fakültesi Eğitim Bilimleri Bölümü, gundogdurezzan@hotmail.com

${ }^{3}$ Doç. Dr., Aksaray Üniversitesi Eğitim Fakültesi Eğitim Bilimleri Bölümü, morsunbulumit@gmail.com

${ }^{4}$ Lisans Öğrencisi, bilgekonal@gmail.com
} 


\section{GIRIŞ}

Bireycilik ve toplulukçuluk yapılarının insan davranışları üzerindeki etkisine ilişkin araştırmalar; sosyoloji, antropoloji, politika, ekonomi gibi birçok alanda yapılmış ve bu etki, farklı boyutlardaki çalışmalarla ortaya konmuştur. Psikoloji literatüründe ise bu yapılarla ilgili araştırmaların özellikle 1980'lerden sonra ivme kazanarak sosyal ve kültürel psikoloji alanlarında ön plana çıktığı görülmektedir (Kağıtçıbaşı, 2007; Triandis,1995; Oyserman ve ark, 2002). Yapılan çalışmalardaki bulgular, bireycilik ve toplulukçuluk yapılarının belli başlı eğilimlerle şekillendiğini göstermektedir. Buna gore ilk eğilim, bütüncül bir bakış açısıyla, Batı kültürü ve bu kültür dahilindeki toplumların bireyci; dünyanın geri kalanının özellikle de Çin, Hindistan, Japonya gibi Asya toplumlarının toplulukçu olduğu yönündedir. Ikinci eğilimde ise Batı ülkelerinde yaşayan göçmenlerin -örneğin ABD'deki Asya ve İspanyol kökenlilertoplulukçu yapıda olduğu önerilmektedir. Dikkat çeken bir diğer eğilim ise modern, sanayileşmiş, şehirleşmiş, hızlı değişen toplumların bireyci; tarıma dayalı, kırsal alanda yaşayan, geleneksel toplumların ise toplulukçu olduğuna dairdir. Bunlara ek olarak bütün kültürlerde üst sınıfta yer alanların bireyci; orta ve alt sınıfta yer alanların ise toplulukçu olduğu yönünde bir eğilimden söz edilmektedir. (Berry ve ark., 2015; Singelis ve ark. 1995).

Bireycilik ve toplulukçuluk yapılarının odağında, bireylerin kendilerini bir grubun parçası mı yoksa gruptan bağımsız bir birey olarak mı tanımladı̆̆ı ayrımı vardır. Buna göre toplulukçular, kendilerini grubun bir parçası olarak tanımlarken; bireyci bireyleri gruptan ayıran bağımsız bir benlik kavramı vardır. Bireyciler için kendi amaçları grubun amaçlarından önceliklidir ve bu doğrultuda bireysel amaçların grubun amaçlarıyla uyumlu hale getirilmesi söz konusu değildir. Toplulukçular ise bireysel amaçlarını grubun amaçları ile uyumlu hale getirmeye çalışırlar ve onlar için grubun amaçları bireyin amaçlarından daha önemlidir (Markus ve Kitayama, 1991). Bireycilik eğilimi gösteren bireylerde, toplumsal davranışın dinamiğinde bireyin kendisi tarafindan üretilmiş içsel süreçler ve tutumlar varken toplulukçu bireyler için bu davranışı yönlendiren; normlar, algılanan görevler ve yükümlülüklerdir. Toplulukçu bireyler için ilişkiler çok önemlidir. Hatta bir ilişkinin maliyeti karından çok fazla olsa bile toplulukçular, bu ilişkiyi devam ettirme eğilimi içindedirler. Bireyciler içinse tersi bir durum söz konudur, dolayısıyla ilişkinin maliyeti, karından fazla ise bu bireyler için ilişki biter (Singelis, 1994).

Kültürlerdeki bireycilik ve toplulukçuluk yapılarını analiz edip tanımlamak, bireylerin sosyal davranışlarını anlama ve yordamada son derece işlevseldir. Fakat kültürleri kendi düzlemlerinde bireyci ve toplulukçu olarak ayırmak mümkün olsa da bir kültürde yaşayan 
insanları, iki zıt kutupta bireyci ya da toplulukçu olarak değerlendirmenin doğruluğu sorgulanmaktadır. Bu bağlamda yapılan araştırmalar da çok boyutluluğa işaret etmektedir (Kağıtçıbaş1, 2007; Oyserman ve ark, 2002;Triandis,1999). Başka bir ifadeyle toplulukçu kültürün bir parçası olan birey, kendini gruptan bağımsız hissedip o yönde davranarak bireyci özellikler gösterebilir ya da bireyci bir kültürde yetişen bir birey kendini toplulukçu hissederek o yönde davranışlar sergileyebilir. Bu doğrultuda da sosyal ve kültürel psikoloji, bireyci ve toplulukçu toplumlar ayrımı yerine birey bazında özerk benlik ya da bağımsız benlik; ilişkisel benlik ya da karşılıklı bağımlı benlik kavramlarını önermektedir. Bu kavramlar, bireyin öznel bağlamdaki değerlendirmeleriyle kendisini nasıl algıladığına ve tanımladığına ilişkindir (Tridianis, 1999).

Özerk ve ilişkisel benlik yapılarını ölçmek için Singelis (1994) tarafından geliştirilen Benlik Kurgusu Ölçeği, aynı kültürde yer alan bireylerin ilişkisellik ve özerklik eğilimlerini baskınlık düzleminde ölçmeyi hedeflemiştir. Başka bir deyişle özerklik ve ilişkisellik eğilimlerini, bireylerde bulunan belli yapılar olarak değil, aynı bireyde her ikisinden de özellikler barındıran ancak bir boyutu baskın olan tutum odağında ölçmeyi öngörmektedir. Singelis (1994) bu yaklaşımla benlik kurgularını -özerklik ve ilişkisellik- kendini başkalarından ayırma ve başkaları ile bütünleşme boyutunda ele almaktadır. Singelis' e (1994) göre özerk benliğin ayırt edici noktası özgünlüğündedir; özerk benliğe sahip birey, kendisini başkalarından ayıran bireysel özelliklerini, bireysel mutluluk ve bireysel kararlarını vurgulamaktadır. İlişkisel benlik eğilimli bireylerin tutumlarını ise grupla işbirliği yapma, kararlarda grubu dikkate alma, mutlu olmanın grupla ilişkilendirilmesi gibi dinamiklere dayandıran Singelis (1994) bu bireyler için özellikle de gruba uyumlu olmayı merkeze almıştır.

Sosyal sermaye; güvene dayal1, maddi olmayan ve insanların birbirlerine güvenmesi sonucu oluşan bir sermayedir. Sosyal sermaye olgusuna dair çalışmalar 1990'lardan itibaren başlamış, özellikle sosyal sermayenin psikoloji, sosyoloji, politika, ekonomi, eğitim, kültür gibi değişkenlerle olan ilişkisi üzerine odaklanılmıştır (Uçar, 2001). Bireyler tek başlarına başaramayacakları veya çok zorlanarak başarabilecekleri hedeflere birbirleri ile iyi ilişkiler kurarak ve bu ilişkilerin zaman içinde devam etmesini sağlayarak ulaşabilirler yahut en azından bu doğrultuda aynı paydada birlikte çalışabilirler. Bu birlikte çalışma tutumu da bireyleri iş imkanları, firsatlar ve yeni ilişkiler bağlamında donatacak bir dizi iletişim ağı ile birbirlerine bağlar. Dolayısıyla bu iletişim ağları da bir kaynak oluşturmaları nedeniyle bir tür sermaye oluşumu gibi değerlendirilebilir. Nitekim bireylerde iletişim ağlarının yarattığı olanakları ve yine bu iletişim ağlarının aracılığıyla oluşan ortak değerleri, iletişim ağlarındaki diğer bireylerle 
paylaşma eğilimi vardır. Buradan hareketle bir bireyin, kurulan ilişkilerde yeni değerler oluşturarak diğerleriyle ortak bir görüşü paylaşması ve tanıdığı insan sayısının fazla olması, o bireyin sosyal sermaye açısından ne kadar zengin olduğunu göstermektedir (Field, 2006).

Güven, ortak değerler ve iletişim ağları ile birbirine bağlanma; sosyal sermayenin en önemli üç öğesidir ve bu öğelerle oluşan bir grup aidiyeti duygusu söz konusudur. Dolayısıyla sadece başka insanları tanımak ya da o insanlarla iletişim halinde olmak, sosyal sermayenin oluşması için yeterli değildir (Field, 2006). Tanınan bu bireylere güvenilmesi, yine bu bireylerden oluşan gruba ait hissedilmesi ve iletişim kurulan bu bireylerle bazı ortak değerlerin varlığına dair inancın olması gerekir.

Sosyal sermaye ile ilgili araştırmalar yapan Coleman, Putnam ve Bourdieu' un çalışmaları incelendiğinde üçünün de ön plana çıkardığı ortak noktalar dikkat çeker. Bu çalışmalarda iletişim ağları ve ortak değerlere aşırı vurgu yapıldığı görülmekle birlikte güvenin, iletişim ağları ve ortak değerlerden çıktığı savunulmaktadır.

Uslaner (2004) ve Fukayama' nın (1998) bakış açısına göre de güven, sosyal sermayenin en önemli değişkenidir. Bu bağlamda bireylerin sadece iletişim ağları kurmaları yeterli değildir. Iletişim ağlarının kaliteli olması ve bireylerin ortak değerler oluşturması için güven duygusu ve bu duyguyla şekillenen ilişkinin olması gereklidir. Uslaner (2004) odağına aldığı güven kavramı için üç tür ayrıma gitmektedir: Stratejik güven, genelleştirilmiş güven ve kurumsal güven.

Stratejik güven, birbirini tanıyan iki birey arasındaki güveni karşılar. Bu güven türünde, iki bireyin birbirleriyle ilgili bilgi düzeylerinin sınırlı olması durumu söz konusudur. Örneğin, önceki deneyimlerinden yola çıkan A kişisi, B kişisine borç verir çünkü bu deneyimlerine dayanarak B kişisinin borcunu ödeyeceğini bilir. A kişisi, B kişisiyle beraber bir tamirat işine birlikte girmez çünkü B kişisinin bu konuda ne kadar yeterli olduğundan emin değildir. Genel anlamda bu güven türünün özellikle tanıdıklar arasında, her yerde olduğundan söz edilebilir. $\mathrm{Bu}$ güven yapısında, insanların birbirlerini tanıma düzeylerindeki artışla birbirlerine güvenme düzeylerindeki artışın orantılı olduğu görülür. Başka bir ifadeyle bireylerin tanıma düzeyleri arttıkça güven düzeylerinde de yükselme eğilimi söz konusudur (Uslaner 2004).

Genelleştirilmiş güven ise birbirini tanımayan bireyler arasındaki güven ilişkisini karşılar. Bireyde, tanımadığı bir kişi ile ilişki kurduğunda aldatılmayacağına ve bu ilişkinin kendisine zarar vermeyeceğine dair bir inanç olmalıdır. Bu perspektiften bakıldığında bireyde, insanların büyük bir kısmının güvenilir olduğu ve insanlar ile rahatlıkla birtakım işlerin yapılıp ilişkiye 
geçilebileceği inancı olmalıdır. Ayrıca Uslaner’ e (2004) göre genelleştirilmiş güven ile ahlaki güven arasında bir süreklilik ilişkisi vardır.

Genelleştirilmiş güvene sahip kişilerin etnik veya dini gruplara katılmaları; iş ilişkilerine, kültürel örgütler ve bunların yaptıkları etkinliklere katılmalarından daha az olasıdır (Uslaner, 2002). Nitekim dine dayalı gruplar, aynı inanca üye insanları bir araya getirerek diğer inançları ise gruplarından dışlama eğilimindedirler. Bu eğilim de hem gruba üye kişilerin tek türden (homojen) hem de dışarıda olanların tek türden (homojen) olmasına neden olmaktadır (Brewer, 1997).

Uslaner'e (2004) göre üçüncü güven türü, kurumlara karş1 olan kurumsal güvendir. Kurumlara güven, genelleştirilmiş güvenle çok yakından bir ilişkiye sahiptir. Bir bireyin genelleştirilmiş güveninin olabilmesinin ön koşulu, kurumlara güvendir. Nitekim birey, içinde yaşadığı devlet kurumlarına güvenince bu durum, onun tanımadığı kişilere güvenmesini de kolaylaştıracaktır. Kurumlara karşı oluşan güven, tanınmayan bir birey ile kurulan ilişkinin olumsuz olsa bile bu kurumlar aracılığıyla giderilebileceği inancını doğurmakta, bu inanç da dolayısıyla genelleştirilmiş güveni artırmaktadır.

“Güçlü bir yasal sistem, bir ilişkide karşılaşılan sorunların maliyetini azaltarak genelleştirilmiş güvenin riskini düşürür.” Dolayısıyla bir ülkedeki yasal sistem ve bu sistemin işleyişine duyulan güven oldukça önemlidir (Uslaner, 2002; Fukayama, 1998).

Güven olgusu diğer bir yönüyle toplumların kültürlerini ve insanların bu kültürlerde birbirleri ile olan etkileşim olanaklarını da yansıtır. Buna göre genelleştirilmiş güven, kolektif kimliklerden çok bireysel değerler etrafında şekillenir. Örneğin Protestan nüfusa sahip olan ülkelerde büyük oranda güçlü bireycilik eğilimleri söz konusudur ve dolayısıyla bu ülkelerde, Katolik ya da Müslüman nüfusun yoğun olduğu toplulukçu ülkelerden daha fazla genelleştirilmiş güven örüntüleri görülür (Allik ve Realo, 2004). Toplumlardaki çeşitlilik de genelleştirilmiş güven için kültür olgusu kadar etkilidir. Toplumlarda görülen çeşitlilik, bireylerin kendilerine benzemeyen insanlarla bağlantı kurmasını sağlamakta ve buna bağlı olarak da genelleştirilmiş güvenin oluşması için birçok firsatın yakalanması durumu ortaya çıkmaktadır (Allik ve Realo, 2004).

Putnam' a (2000) göre Amerikan toplumunda son y1llarda görülen genel mutluluktaki düşüş, suç oranlarındaki hızlı artışla ve insanların yönetime karşı kayıtsızlığıyla yakından ilgilidir. Buna ek olarak Putnam, Amerika' da en önemli eğlence aracı olarak televizyonun ilk sıraları almasını ve kadınların çalışma hayatına katılmasının sonuçlarını da sosyal sermaye 
düzeyinin düşmesine bağlamaktadır. Bunun yanı sıra sosyal sermayenin yüksek olduğu toplum ve bölgelerdeyse insanların mutlu olduğu, sağlıklı oldukları sosyal ortamın çok daha güvenli olduğunu bulgulayan araştırmalar vardır (Field, 2006).

Yukarıda anlatılanlar göz önüne alındığında sosyal sermayenin en önemli boyutu kültürden etkileniyorsa Türk toplumunda bununla ilgili nasıl bir yapı vardır? Benlik biçimlerindeki genel eğilim, benliği özerk ve karşılıklı bağımlı olarak ayırma yönündedir (Singelis, 1994; Markus ve Kitiyama, 1991,2001). Özerk benlik yapısına sahip bireylerin benlik tanımları, kendilerini içinde bulundukları gruplardan ayıran özellikler odağındadır. Dolayısıyla bu bireyler kendilerini tanımlarken başkalarının duygu, düşünce ve eylemlerini değil; kendilerine özgü içsel duygu, düşünce ve eylemlerini kullanmaktadırlar. Özellikle Batı toplumlarında dikkat çeken bu benlik biçiminde bireyler bağımsızlıklarına değer verirler ve onlar için özgün olmak önemlidir. Bu bireylerdeki temel tutum, kendi kararlarını kendileri verip bunları bağımsız bir biçimde uygulamaktır. Karşılıklı bağımlı benliğe sahip olan bireylerde ise kendini tanımlama, başkaları ile ilişkiler odağındadır ve dolayısıyla bu bireylerde davranışlarını belirleyenin genellikle başkalarının duygu, düşünce ve eylemleri olduğuna dair bir durumu kabul etme eğilimi vardır. Karşılıklı bağımlı benlik yapısındaki birey, kendini daha çok içinde bulunduğu aile ya da dini cemaat gibi sosyal gruplara atıfta bulunarak tanımlamaktadır. Özerk benliğe sahip bireylerin içinde bulundukları gruplara uyma ve grup düşüncesini benimseme davranışı daha azken, karşılıklı benlik yapısındaki bireyler, buldukları gruplara uymayı ve grup düşüncesini benimsemeyi yeğlerler. Dolayısıyla karşılıklı bağımlı benliğe sahip bireylerin grup kararına karşı çıkma davranışı, özerk benlikteki bireylere kıyasla daha az beklenen bir durumdur.

Türkiye'de sosyal sermaye üzerine yapılan araştırmalar, genel olarak güven ve sosyal etkinliklere katılımı ölçerek sosyal sermayeyi yordamaya dayalı çalışmalar ile okullarda yapılanlar olarak karşımıza çıkmaktadır. Erdoğan (2003) tarafından yapılan çalışmada sosyal sermayenin Türk toplumunda düşük olduğu bulgulanmıştır. Ölçekte yer alan “Türkiye'de insanların çoğunluğuna güvenilir.” maddesi, bu araştırmalardaki en önemli ölçüt olmaktadır.

Sosyal sermayenin bireyci toplumlarda daha çok var olduğu, toplulukçu toplumlarda ise olmadığı yönünde değerlendirmeler vardır. Nitekim toplulukçu kültürlerde bireyler, olaylara grubun bir parçası olarak tepki verme eğilimindedirler. Bu bağlamda düşünüldüğünde toplulukçu kültürlerde genelleştirilmiş güvenin ortak değerler düzeyinin düşük olduğu önerilmektedir (Allik ve Realo, 2004; Uslaner, 2004). 
Şimdiye kadar değinildiği üzere sosyal sermayeyi etkileyen pek çok değişken vardır. Ulaşılabilen alanyazın kapsamında sosyal sermaye ile ilgili yapılan çalışmalar incelendiğinde, Türk kültüründe Singelis' in benlik kurguları ile sosyal sermaye ilişkisini inceleyen ve kadınlar ile erkeklerin sosyal sermaye düzeylerini bulgulayan bir araştırmaya rastlanmamıştır. $\mathrm{Bu}$ araştırma, sosyal sermaye öğeleri ile cinsiyetler arası ilişkileri göstererek bu değişkenlerin yönü hakkında bilgi verebilir.

$\mathrm{Bu}$ araştırmanın temel amacı, sosyal sermaye öğeleri olan stratejik güven, genelleştirilmiş güven, kurumsal güven ve ortak değerlerin; özerk ve ilişkisel benlik kurgularını kadınlarda ve erkeklerde yordayıp yordamadığına ilişkindir.

\section{YÖNTEM}

$\mathrm{Bu}$ araştırma, mevcut durumu sorgulayan betimsel bir araştırmadır. Türkiye'de beliren yetişkinlik döneminde sosyal sermayenin benlik kurguları üzerindeki etkisini incelemek amacıyla ilişkisel tarama modeline dayanarak araştırma gerçekleştirilmiştir. Tarama modelleri, geçmişte ya da halen var olan bir durumu var olduğu şekliyle betimlemeyi amaçlayan araştırma yaklaşımlarıdır (Karasar, 2004). Araştırmada, ilgili değişkenlerin beliren yetişkinlik döneminde sosyal sermayenin benlik kurgularına olan etkilerini içeren çoklu regresyon modeli geliştirilip test edilmiştir.

\section{Araştırma Grubu}

Katılımcıların tamamı Aksaray Üniversitesinde eğitim alan öğrencilerden oluşmaktadır. Ölçme araçlarının uygulanacağı bireyler, "18-26 yaş aralığında (beliren yetişkinlik döneminde) olmak" durumu dikkate alınarak, amaçlı (purposive) örnekleme yöntemlerinden maksimum çeşitlilik yöntemi ile belirlenmiştir. Amaçlı örneklemde araştırmacı, evrenle ilgili daha önceki kuramsal bilgilere ve kendi bilgilerine ve araştırmanın özel amacına dayanarak bir örneklem belirlemektedir (Fraenkel ve Wallen, 1993). Bu örneklemenin temeli, araştırmanın amaçları doğrultusunda bir evrenin temsilci bir örneği yerine, amaçlı olarak bir ya da birkaç alt kesmini örnek olarak almak ve evrenin araştırma problemine en uygun bir kesmini gözlem konusu yapmaktır (Sencer, 1989). Bu örnekleme yönteminin, evren değerleri hakkında önemli ipuçları vereceği ifade edilmektedir (Büyüköztürk, Kılıç-Çakmak, Akgün, Karadeniz ve Demirel, 2008).

Araştırma kapsamında kullanılan veri toplama araçları 300 katılımcıya uygulanmıştır. Ölçek maddelerinin çoğunu boş bırakan (en az \% 5'ini) ya da merkeze kayma hatalarının 
gözlendiği toplam 55 kişi veri setinden çıarılmışırı. 247 kişi üzerinde yapılan aykırı değer analizleri sonucunda da 13 gözlem analiz dışı bırakılmıştır. Sonuç olarak, araştırma grubu Aksaray Üniversitesinde öğrenim görmekte olan 234 öğrenciden oluşmaktadır. Katılımcıların $\% 66,7 \mathrm{kız} \% 33,3$ erkektir. Çalışma grubundaki katılımcıların yaşları 18-26 arasında değişmektedir ( $\overline{\mathrm{X}}$ yaş=20.46; Sd: 1,70$)$.

\section{Veri Toplama Araçları}

Benlik kurgularını ölçmek için Singelis (1994) tarafından geliştirilmiş, Wasti ve Erdil (2007) tarafından da adaptasyonu yapılmış Benlik Kurgusu Ölçeği kullanılmıştır. Ölçek, ilişkisellik ve özerklik boyutlarını ölçen 15 'er maddeden oluşmaktadır. Katılımcılardan, ölçekteki her bir maddenin kendi durumlarını ne ölçüde yansıttığını 1 (hiç uygun değil) ile 7 (tamamen uygun) arasında puan vererek derecelendirmeleri istenmektedir. Özerklik ölçeğinin cronbach alfa iç tutarlılık katsayısı .75 , ilişkisellik ölçeğinin cronbach alfa iç tutarlılık katsayısı .73 olarak bulunmuştur.

Sosyal sermayeyi ölçmek amacıyla Uçar (2011) tarafından geliştirilen 4 boyutlu ölçek kullanılmıştır. Sosyal sermayeyi yordayabilmek için stratejik güvenin düşük ya da genelleştirilmiş güven ve kurumsal güvenin yüksek olması; ayrıca ortak değerler ve grup üyeliğinden yüksek toplam puanlar alınması gerekmektedir.

Tanıdıklar arası güveni ölçmek için Uçar (2011) tarafından geliştirilmiş olan Stratejik Güven Ölçeği kullanılmıştır. Ölçek, 9 maddeden oluşan tek boyutlu 5 dereceli Likert tipi bir ölçektir. Ölçekten alınan yüksek puan stratejik güvenin fazla olduğunu, düşük puan stratejik güvenin düşük olduğunu göstermektedir $\mathrm{Bu}$ çalışmada ölçeğin Cronbach alfa iç tutarlılık katsayıs1 0.87 olarak bulunmuştur.

Genelleştirilmiş güveni ölçmek için Uçar (2011) tarafindan geliştirilmiş olan Genelleştirilmiş Güven Ölçeği kullanılmıştır. Ölçek, 11 maddeden oluşan tek boyutlu 5 dereceli Likert tipi bir ölçektir. Ölçekten alınan yüksek puan genelleştirilmiş güvenin fazla olduğunu, düşük puan genelleştirilmiş güvenin düşük olduğunu göstermektedir. Bu çalışmada ölçeğin Cronbach alfa iç tutarlılık katsayısı 0.79 olarak bulunmuştur.

Kurumsal güveni ölçmek için Uçar (2011) tarafindan geliştirilmiş olan Kurumsal Güven Ölçeği kullanılmıştır. Ölçek, 16 maddeden oluşan tek boyutlu 5 dereceli Likert tipi bir ölçektir. Ölçekten alınan yüksek puan kurumsal güvenin fazla olduğunu, düşük puan kurumsal güvenin düşük olduğunu göstermektedir. Bu çalışmada ölçeğin Cronbach alfa iç tutarlılık katsayısı 0 . 79 olarak bulunmuştur. 
Ortak değerleri ölçmek için Uçar (2011) tarafından geliştirilmiş olan Ortak Değerler Ölçeği kullanılmıştır. Ölçek, 8 maddeden oluşan tek boyutlu 5 dereceli Likert tipi bir ölçektir. Ölçekten alınan yüksek puan ortak değerlerin fazla olduğunu, düşük puan ortak değerlerin düşük olduğunu göstermektedir. Bu çalışmada ölçeğin Cronbach alfa iç tutarlılık katsayısı 0 . 79 olarak bulunmuştur. Ayrı ayrı boyutlar incelenebileceği gibi toplam puanlar da alınıp sosyal sermaye düzeyi ölçülebilmektedir.

\section{Verilerin Analizi}

Araştırmadan elde edilen verilerin istatistiksel çözümlemeleri SPSS 17.00 paket programı kullanılarak yapılmıştır. Katılımcıların demografik özelliklerinin analizinde frekans ve yüzde dağılımı kullanılmıştır.

\section{Süreç}

Araştırmada veriler, bireysel uygulama ve grup uygulaması şeklinde toplanmıştır. Veriler üniversitede ders saatleri içinde dersin yürütücüsünün izni ve yardımıyla toplanmıştır. Ölçeklerin uygulanması 30-40 dakika arasında değişmiştir. Araştırma verileri Aksaray ilinde Nisan 2015 - Mayıs 2016 tarihleri arasında toplanmıştır. Veriler toplanırken gönüllülük ilkesi esas alınmış, katılımcılara öncelikle araştırmanın amacına yönelik kısa bir bilgi verilmiş ve ardından araştırmaya katılmak isteyen katılımcılara ölçekler verilmiştir. Ayrıca, gerekli durumlarda katılımcılara ek açıklamalar yapılmıştır. Katılımcılardan kimlik bilgileri istenmemiştir.

\section{BULGULAR}

Katılımcıların ölçeklerden aldıkları puanlara ait aritmetik ortalamalar aşağıda sunulmuştur:

Tablo 1. Betimsel istatistikler sosyal sermaye ve benlik kurguları ortalamaları

\begin{tabular}{|c|c|c|c|c|c|c|}
\hline & & $\overline{\mathrm{X}}$ & Ss & Skewness & Kurtosis & Range \\
\hline \multirow[t]{6}{*}{ Kadın } & Özerk benlik kurgusu & 53,61 & 6,41 &, 070 & .209 & 32,00 \\
\hline & İlişkisel benlik kurgusu & 51,09 & 5,86 &,- 062 & -.234 & 28,00 \\
\hline & Stratejik Güven & 34,80 & 5,12 &,- 376 & .596 & 25,00 \\
\hline & Genelleştirilmiş Güven & 29,76 & 4,18 &,- 445 & .925 & 27,00 \\
\hline & Kurumsal Güven & 47,46 & 9,67 &, 090 & .475 & 51,00 \\
\hline & Ortak Değerler & 30,37 & 4,35 &,- 274 & .353 & 23,00 \\
\hline \multirow[t]{6}{*}{ Erkek } & Özerk benlik kurgusu & 54,20 & 7,08 &, 072 & .126 & 33,00 \\
\hline & İlişkisel benlik kurgusu & 51,97 & 7,03 &,- 179 & -.025 & 33,00 \\
\hline & Stratejik Güven & 35,06 & 5,40 &,- 288 & .102 & 24,00 \\
\hline & Genelleştirilmiş Güven & 30,82 & 3,02 &,- 095 & .1 .298 & 19,00 \\
\hline & Kurumsal Güven & 48,24 & 9,44 &,- 318 & .131 & 47,00 \\
\hline & Ortak Değerler & 30,79 & 4,72 &,- 222 & -.032 & 22,00 \\
\hline
\end{tabular}


Tablo 2. Sosyal sermaye ve benlik kurguları arasındaki korelasyonlar

\begin{tabular}{|c|c|c|c|c|c|c|c|}
\hline & & 1 & 2 & 3 & 4 & 5 & 6 \\
\hline \multirow[t]{6}{*}{ Kadın } & 1.Özerk benlik kurgusu & 1 & .028 & $.182 *$ & -.112 & -083 & .145 \\
\hline & 2.İlişkisel benlik kurgusu & & 1 & $.281 * *$ & .068 & .039 & $.321 * *$ \\
\hline & 3.Stratejik Güven & & & 1 & .064 & .080 & $.622 * *$ \\
\hline & 4.Genelleştirilmiş Güven & & & & 1 & $.204 *$ & -.015 \\
\hline & 5.Kurumsal Güven & & & & & 1 & .135 \\
\hline & 6. Ortak Değerler & & & & & & 1 \\
\hline \multirow[t]{6}{*}{ Erkek } & 1.Özerk benlik kurgusu & 1 & $.477 * *$ & $.404 * *$ & 033 & -.075 & $.412 * *$ \\
\hline & 2.İlişkisel benlik kurgusu & & 1 & $.424 * *$ & -.193 & -.010 & $.372 * *$ \\
\hline & 3.Stratejik Güven & & & 1 & -.083 & -.101 & $591 * *$ \\
\hline & 4.Genelleştirilmiş Güven & & & & 1 & .206 & -.066 \\
\hline & 5.Kurumsal Güven & & & & & 1 & .110 \\
\hline & 6. Ortak Değerler & & & & & & 1 \\
\hline
\end{tabular}

Tablo 3. Stratejik güven, genelleştirilmiş güven, kurumsal güven ve ortak değerlerin ilişkisel benlik kurgusunu yordayıp yordamadığına ilişkin regresyon analizi

\begin{tabular}{|c|c|c|c|c|c|c|c|c|c|}
\hline Model & B & $\begin{array}{c}\text { Sd. } \\
\text { Hata }\end{array}$ & B & $\mathrm{T}$ & $\mathrm{p}$ & $\mathrm{R}$ & $\mathrm{R}^{2}$ & F & $\mathrm{P}$ \\
\hline Sabit & 35.154 & 3.769 & .384 & 9.326 & .000 &, 38 &, 14 & 9.895 & $.000^{\mathrm{a}}$ \\
\hline
\end{tabular}

a. Yordayanlar: (Sabit), Stratejik güven, Genelleştirilmiş güven, Kurumsal güven ve Ortak değerler b. Yordanan: İlişkisel benlik

Stratejik güven, genelleştirilmiş güven, kurumsal güven ve ortak değerlerin özerk ve ilişkisel benlik kurgularını yordayıp yordamadığını belirlemek için çoklu regresyon analizi yapılmıştır. Yapılan regresyon analizi sonucunda stratejik güven, genelleştirilmiş güven, kurumsal güven ve ortak değerlerin ilişkisel benlik kurgusunun 0.05 düzeyinde anlamlı bir yordayicısı olduğu bulunmuştur $\left(\mathrm{R}=0,384, \mathrm{R}^{2}=0,147, \mathrm{~F}=14,806, \mathrm{P}<0.05\right)$. Buradan hareketle stratejik güven, genelleştirilmiş güven, kurumsal güven ve ortak değerlerle ilişkisel benlik kurgusu arasında .05 düzeyinde anlamlı bir ilişki olduğu görülmekle birlikte ilişkisel benlik kurgusu ortalamalarına ilişkin toplam varyansın \% 15'nin stratejik güven, genelleştirilmiş güven, kurumsal güven ve ortak değerleri yordadığı yorumu yapılabilir.

Tablo 4. Stratejik güven, genelleştirilmiş güven, kurumsal güven ve ortak değerlerin ilişkisel benlik kurgusunu yordamasına ilişkin coefficient tablosu

\begin{tabular}{|c|c|c|c|c|c|c|c|c|}
\hline Model & B & $\begin{array}{c}\text { Sd. } \\
\text { hata }\end{array}$ & $\mathrm{B}$ & $\mathrm{t}$ & $\mathrm{p}$ & Ikili r & Kismı r & VIF \\
\hline Sabit & 35.154 & 3.714 & & 9.326 & .000 & & & \\
\hline Stratejik Güven & .249 & .094 & .206 & 2.663 & .008 & .336 & .162 & 1.611 \\
\hline Genelleştirilmiş Güven & -.076 & .072 & -.067 & -1.054 & .293 & -.078 & -.064 & 1.089 \\
\hline Kurumsal Güven & -.007 & .042 & .011 & .169 & .866 & .011 & .011 & 1.107 \\
\hline Ortak Değerler & -.298 & .110 & .212 & 2.700 & .007 & .176 & .165 & 1.652 \\
\hline
\end{tabular}

Regresyon analizindeki $\beta$ değerleri incelendiğinde stratejik güven, ilişkisel benlik kurgusu ortalamalar arası varyansın \%21' ini açıklamaktadır $(\beta=.206, \mathrm{p}<.005, \mathrm{t}=2.663)$. Ortak değerlerin de ilişkisel benlik kurgusunun ortalamalar arası varyansın \%21' ini açıkladığı ( $=.212, \mathrm{p}<.005, \mathrm{t}=2.700)$; genelleştirilmiş güven $(\beta=-.067, \mathrm{p}<.293, \mathrm{t}=1.054)$ ve kurumlara güvenin ( $(=.011, \mathrm{p}<.866, \mathrm{t}=.69)$ ise ilişkisel benlik kurgusunu yordamadığı görülmektedir. 
Tablo 5. Stratejik güven, genelleştirilmiş güven, kurumsal güven ve ortak değerlerin özerk benlik kurgusunu yordayıp yordamadığına ilişkin regresyon analizi

\begin{tabular}{|c|c|c|c|c|c|c|c|c|c|}
\hline Model & B & $\begin{array}{r}\text { Sd. } \\
\text { hata }\end{array}$ & B & $\mathrm{T}$ & $\mathrm{p}$ & $\mathrm{R}$ & $\mathrm{R}^{2}$ & $\mathrm{~F}$ & $\mathrm{P}$ \\
\hline Sabit & 45.379 & 4.083 & .320 & 11.115 & .000 &, $320^{\mathrm{a}}$ & ,103 & 6.651 & $.000^{\mathrm{a}}$ \\
\hline
\end{tabular}

a. Yordayanlar: (Sabit), Stratejik güven, Genelleştirilmiş güven, Kurumsal güven ve Ortak değerler b. Yordanan: Özerk benlik

Regresyon analizi sonucunda stratejik güven, genelleştirilmiş güven, kurumsal güven ve ortak değerlerin özerk benlik kurgusunun 0.05 düzeyinde anlamlı bir yordayıcısı olduğu bulgulanmıştır $\left(\mathrm{R}=0,320, \mathrm{R}^{2}=0,103, \mathrm{~F}=7,651, \mathrm{P}<0.05\right)$. Buradan hareketle stratejik güven, genelleştirilmiş güven, kurumsal güven ve ortak değerlerle özerk benlik kurgusu arasında .05 düzeyinde anlamlı bir ilişki olduğu, özerk benlik kurgusu ortalamalarına ilişkin toplam varyansın \% 10 'nun stratejik güven, genelleştirilmiş güven, kurumsal güven ve ortak değerler ile açıklandığı sonucuna ulaşılmıştır.

Tablo 6. Stratejik güven, genelleştirilmiş güven, kurumsal güven ve ortak değerlerin özerk benlik kurgusunu yordamasına ilişkin coefficient tablosu

\begin{tabular}{|c|c|c|c|c|c|c|c|c|}
\hline Model & B & $\begin{array}{l}\text { Sd. } \\
\text { hata }\end{array}$ & $\beta$ & $\mathrm{t}$ & $\mathrm{p}$ & Ikili r & Kismi r & VIF \\
\hline Sabit & 45.379 & 4.083 & & 11.198 & .000 & & & \\
\hline Stratejik Güven & .229 & .101 & .180 & 2.263 & .025 & .264 & .142 & 1.611 \\
\hline Genelleştirilmiş Güven & -.132 & .078 & -.111 & -1.695 & .092 & -.138 & -.106 & 1.089 \\
\hline Kurumsal Güven & -.048 & .046 & -.046 & -1.058 & .291 & .078 & -.066 & 1.107 \\
\hline Ortak Değerler & .207 & .119 & .140 & 1.736 & .084 & .247 & .109 & 1.652 \\
\hline
\end{tabular}

Regresyon analizindeki $\beta$ değerleri incelendiğinde stratejik güvenin özerk benlik kurgusuna ilişkin ortalamalar arası varyansın \%18 ini açıkladığı görülmektedir $(ß=.180, \mathrm{p}<$ $.025, \mathrm{t}=2.263)$. Genelleştirilmiş güven $(\beta=-.111, \mathrm{p}<.092, \mathrm{t}=-1.695)$, kurumsal güven $(\beta=-.046$, $\mathrm{p}<.291, \mathrm{t}=-1.058)$ ve ortak değerler $(\beta=.140, \mathrm{p}<.084, \mathrm{t}=1.736)$ ise özerk benlik kurgusunu yordamamıştır.

Tablo 7. Kadınlar ve erkeklerde stratejik güven, genelleştirilmiş güven, kurumsal güven ve ortak değerlerin ilişkisel benlik kurgusunu yordayıp yordamadığına ilişkin regresyon analizi

\begin{tabular}{|c|c|c|c|c|c|c|c|c|c|c|}
\hline & Model & B & $\begin{array}{l}\text { Sd. } \\
\text { hata }\end{array}$ & B & $\mathrm{t}$ & $\mathrm{p}$ & $\mathrm{R}$ & $\mathrm{R}^{2}$ & $\mathrm{~F}$ & P \\
\hline Kadın & Sabit & 35.361 & 4,290 &, 338 & 8,243 & .000 &, $338^{\mathrm{a}}$ & ,114 & 4.823 &, 001 \\
\hline Erkek & & 37,346 & 7,635 & ,495 & 4,891 & &, $495^{\mathrm{a}}$ & 245 & 5.938 &, 001 \\
\hline
\end{tabular}

a. Yordayanlar: (Sabit), Stratejik güven, genelleştirilmiş güven, kurumsal güven ve ortak değerler b. Yordanan: İlişkisel benlik

Kadınlar ve erkeklerin benlik kurguları ile stratejik güven, genelleştirilmiş güven, kurumsal güven ve ortak değerler arasındaki ilişkilerinin incelenmesi için çoklu regresyon analizi yapılmıştır. Tablo.7'deki regresyon analizi sonuçlarına göre stratejik güven, genelleştirilmiş güven, kurumsal güven ve ortak değerlerin kadınlarda ilişkisel benlik 
kurgusunun 0.05 düzeyinde anlamlı bir yordayıcısı olduğu bulunmuştur $\left(\mathrm{R}=0,338, \mathrm{R}^{2}=0,114\right.$, $\mathrm{F}=4.823, \mathrm{P}<0.05)$. Buradan hareketle stratejik güven, genelleştirilmiş güven, kurumsal güven ve ortak değerlerle ilişkisel benlik kurgusu arasında .05 düzeyinde anlamlı bir ilişki olduğu görülmekle birlikte ilişkisel benlik kurgusu ortalamalarına ilişkin toplam varyansın \% 11 inin stratejik güven, genelleştirilmiş güven, kurumsal güven ve ortak değerleri yordadığı yorumu yapılabilir.

Tablo.7'deki regresyon analizi sonuçları incelendiğinde stratejik güven, genelleştirilmiş güven, kurumsal güven ve ortak değerlerin kadınlarda özerk benlik kurgusunun 0.05 düzeyinde anlamlı bir yordayıcısı olduğu görülmektedir $\left(\mathrm{R}=0,495, \quad \mathrm{R}^{2}=0,245, \quad \mathrm{~F}=5.938, \quad \mathrm{P}<0.05\right)$. Buradan hareketle stratejik güven, genelleştirilmiş güven, kurumsal güven ve ortak değerlerle ilişkisel benlik kurgusu arasında .05 düzeyinde anlamlı bir ilişski olduğu, ilişkisel benlik kurgusu ortalamalarına ilişkin toplam varyansın \% 25' inin stratejik güven, genelleştirilmiş güven, kurumsal güven ve ortak değerler tarafından yordandığı yorumu yapılabilir.

Tablo 8. Kadınlar ve erkeklerde stratejik güven, genelleştirilmiş güven, kurumsal güven ve ortak değerlerin ilişkisel benlik kurgusunu yordamasına ilişkin coefficient tablosu

\begin{tabular}{|c|c|c|c|c|c|c|c|c|c|}
\hline & & B & Sd. & & & & & & \\
\hline & Model & & Hata & $\beta$ & $\mathrm{T}$ & $\mathrm{P}$ & Ikili r & Kism1 r & VIF \\
\hline \multirow[t]{5}{*}{ Kadın } & Sabit & 35,361 & 4,290 & & 8,243 & ,000 & & & \\
\hline & Stratejik Güven &, 149 &, 113 &, 130 & 1,321 &, 188 & ,281 &, 101 & 1,654 \\
\hline & Genelleştirilmiş Güven &, 018 & ,084 &, 017 & ,208 & ,836 &, 012 &, 016 & 1,120 \\
\hline & Kurumsal Güven &,- 006 & ,049 &,- 009 &,- 116 & ,908 & 039 &,- 009 & 1,125 \\
\hline & Ortak Değerler &, 326 &, 134 & ,242 & 2,432 &, 016 &, 321 &, 186 & 1,684 \\
\hline \multirow[t]{5}{*}{ Erkek } & Sabit & 37,346 & 7,635 & & 4,891 &, 000 & & & \\
\hline & Stratejik Güven & ,388 & , 168 & ,298 & 2,308 &, 024 & ,424 & ,235 & 1,611 \\
\hline & Genelleştirilmiş Güven &,- 278 &, 137 &,- 213 & $-2,034$ & 046 &,- 266 &,- 207 & 1,057 \\
\hline & Kurumsal Güven &, 030 & 079 &, 040 & ,381 & 705 &,- 010 & ,039 & 1,094 \\
\hline & Ortak Değerler &, 252 &, 193 &, 169 & 1,311 & ,194 & ,372 &, 133 & 1,615 \\
\hline
\end{tabular}

Tablo.8'de regresyon analizindeki $\beta$ değerleri incelendiğinde ortak değerlerin ilişkisel benlik kurgusuna ilişkin ortamalar arası varyansın \%24' ünü açıkladığı görülmektedir ( $\beta=.242$, $\mathrm{p}<.005, \mathrm{t}=2.432)$. Stratejik güven $(\beta=.130, \mathrm{p}<.188, \mathrm{t}=1.321)$, genelleştirilmiş güven $(\beta=.017$, $\mathrm{p}<.836, \mathrm{t}=208)$ ve kurumlara güvenin $(\beta=-.009, \mathrm{p}<-.009, \mathrm{t}=-.116)$ ise ilişkisel benlik kurgusunu yordamadığı görülmektedir. Erkeklerde $\beta$ değerleri incelendiğinde stratejik güvenin, ilişkisel benlik kurgusuna ilişkin ortalamalar arası varyansın \%30’ unu açıkladığı ( $(B=.298, \mathrm{p}<$ .024, $\mathrm{t}=2.308)$ görülmektedir. Genelleştirilmiş güven ise ilişkisel benlik kurgusuna ilişkin ortalamalar arası varyansın \%21' ini açıklamaktadır $(\beta=-.213, \mathrm{p}<.046, \mathrm{t}=-2.034)$. Ancak değerler negatif yöndedir ve bu bulgudan hareketle genelleştirilmiş güven artıkça ilişkisel benlik kurgusunun azaldığı yorumu yapılabilir. Kurumsal güven $(\beta=-.030, \mathrm{p}<.705, \mathrm{t}=.381)$ ve ortak değerler $(\beta=.193, \mathrm{p}<.194, \mathrm{t}=1.311)$ ise ilişkisel benlik kurgusunu yordamamıştır. 
Tablo 9. Kadınlar ve erkeklerde stratejik güven, genelleştirilmiş güven, kurumsal güven ve ortak değerlerin özerk benlik kurgusunu yordayıp yordamadığına ilişkin regresyon analizi

\begin{tabular}{|c|c|c|c|c|c|c|c|c|c|c|}
\hline & Model & B & $\begin{array}{r}\text { Sd. } \\
\text { hata }\end{array}$ & $\beta$ & $\mathrm{t}$ & $\mathrm{p}$ & $\mathrm{R}$ & $\mathrm{R}^{2}$ & $\mathrm{~F}$ & $\mathrm{P}$ \\
\hline Kadın & Sabit & 50,797 & 4,819 & ,258 & 10,541 & .000 &, $258^{\mathrm{a}}$ & ,067 & 2,700 & ,001 \\
\hline Erkek & & 35,058 & 7,829 & ,466 & 4,478 & &, $466^{\mathrm{a}}$ &, 217 & 5,072 & ,001 \\
\hline
\end{tabular}

a. Yordayanlar: (Sabit), Stratejik güven, genelleştirilmiş güven, kurumsal güven ve ortak değerler b. Yordanan: Özerk benlik

Tablo.9'daki regresyon analizi sonuçlarına göre stratejik güven, genelleştirilmiş güven, kurumsal güven ve ortak değerlerin özerk benlik kurgusunun kadınlarda 0.05 düzeyinde anlamlı bir yordayıcısı olduğu bulunmuştur $\left(\mathrm{R}=0,258, \mathrm{R}^{2}=0,67, \mathrm{~F}=2.700, \mathrm{P}<0.05\right)$. Buradan hareketle stratejik güven, genelleştirilmiş güven, kurumsal güven ve ortak değerlerle özerk benlik kurgusu arasında .05 düzeyinde anlamlı bir ilişki olduğu görülmekle birlikte ilişkisel benlik kurgusu ortalamalarına ilişkin toplam varyansın $\% \quad 7 \quad$ sinin stratejik güven, genelleştirilmiş güven, kurumsal güven ve ortak değerleri yordadığı yorumu yapılabilir.

Tablo.9'deki regresyon analizi sonuçları incelendiğinde stratejik güven, genelleştirilmiş güven, kurumsal güven ve ortak değerlerin erkeklerde özerk benlik kurgusunun 0.05 düzeyinde anlamlı bir yordayıcısı olduğu görülmektedir $\left(\mathrm{R}=0,466, \quad \mathrm{R}^{2}=0,217, \quad \mathrm{~F}=5.072, \quad \mathrm{P}<0.05\right)$. Buradan hareketle stratejik güven, genelleştirilmiş güven, kurumsal güven ve ortak değerlerle özerk benlik kurgusu arasında .05 düzeyinde anlamlı bir ilişki olduğu görülmekte, özerk benlik kurgusu ortalamalarına ilişkin toplam varyansın \% 22' sinin stratejik güven, genelleştirilmiş güven, kurumsal güven ve ortak değerler tarafından yordandığı yorumuna ulaşılmaktadır.

Tablo 10. Kadınlar ve erkeklerde stratejik güven, genelleştirilmiş güven, kurumsal güven ve ortak değerlerin özerk benlik kurgusunu yordamasına ilişkin coefficient tablosu

\begin{tabular}{|c|c|c|c|c|c|c|c|c|c|}
\hline & & B & Sd. & & & & & & \\
\hline & Model & & Hata & $\mathrm{B}$ & $\mathrm{t}$ & $\mathrm{P}$ & Ikili r & Kisme r & VIF \\
\hline \multirow[t]{5}{*}{ Kadın } & Sabit & 50,797 & 4,819 & & 10,541 & ,000 & & & \\
\hline & Stratejik Güven &, 215 & ,127 & ,171 & 1,696 & ,092 & ,182 & 133 & 1,654 \\
\hline & Genelleștirilmiş Güven &,- 175 & 095 &,- 154 & $-1,854$ & 066 &,- 162 &,- 146 & 1,120 \\
\hline & Kurumsal Güven &,- 037 & 055 &,- 056 &,- 675 &, 501 &,- 083 &,- 053 & 1,125 \\
\hline & Ortak Değerler &, 059 &, 150 &, 040 &, 392 & ,696 &, 145 &, 031 & 1,684 \\
\hline \multirow[t]{5}{*}{ Erkek } & Sabit & 35,058 & 7,829 & & 4,478 & 000 & & & \\
\hline & Stratejik Güven & ,290 &, 172 &, 221 & 1,685 & ,096 & ,404 &, 174 & 1,611 \\
\hline & Genelleștirilmiş Güven &,- 049 & 140 &,- 037 &,- 349 & 728 &,- 113 &,- 036 & 1,057 \\
\hline & Kurumsal Güven &,- 058 & 081 &,- 078 &,- 717 & ,476 &,- 075 &,- 074 & 1,094 \\
\hline & Ortak Değerler &, 429 & 197 & ,286 & 2,175 & 033 &, 412 & ,225 & 1,615 \\
\hline
\end{tabular}

Tablo.10'da yer alan regresyon analizindeki $\beta$ değerleri incelendiğinde kadınlarda stratejik güven $(~(==-.171, \mathrm{p}<.092, \mathrm{t}=1.696)$, genelleştirilmiş güven $(\beta=-.154, \mathrm{p}<.066$, $\mathrm{t}=1.854)$, kurumsal güven $(\beta=-.042, \mathrm{p}<.612, \mathrm{t}=-.509)$ ve ortak değerlerin $(\beta=-.056, \mathrm{p}<.501$, t=.-.675) özerk benlik kurgusunu yordamadığı görülmektedir. $\mathrm{Bu}$ tablo, sözü edilen 
değişkenlerin birlikteyken varyansın \%7' sini açıkladığını ancak tek başlarına ele alındıklarında özerk benlik kurgusuna ilişkin ortalamalar arası varyansı açıklamadığını göstermektedir.

Erkeklerde ise $\beta$ değerleri incelendiğinde ortak değerlerin özerk benlik kurgusuna ilişkin ortalamalar arası varyansın \%29' unu açıkladığı $(\beta=.286, \mathrm{p}<.033, \mathrm{t}=2.175)$ görülmekle birlikte, stratejik güven $(~(\beta=-.221, \mathrm{p}<.096, \mathrm{t}=1.1685)$, genelleştirilmiş güven $(\beta=-.037, \mathrm{p}<$ $.728, \mathrm{t}=-.349)$ ve kurumsal güvenin $(\beta=-.078, \mathrm{p}<.476, \mathrm{t}=-.717)$ özerk benliği anlamlı olarak yordamadı̆̆ görülmektedir.

\section{SONUÇ, TARTIŞMA VE ÖNERILER}

Araştırma sonucunda stratejik güven, ilişkisel benlik kurgusunu yordamış ( $(=.206, p<$ $.005, \mathrm{t}=2.663$ ), genelleştirilmiş güven ve kurumsal güven ise yordamamıştır. $\mathrm{Bu}$ bulgu alanyazın ile paraleldir. Tanıdık ya da yakın ilişkide olan bireyler arasındaki güven, toplulukçu kültürlerde daha fazladır (Allik ve Realo, 2004; Ulsaner, 2002, 2004). Türk toplumunda da stratejik güven, ilişkisel benlik kurgusunu yordamakta ancak genelleştirilmiş güven ve kurumsal güveni yordamamaktadır. Ortak değerlerin ilişkisel benliği yordadığı bulgulanmıştır $(ß=.212, \mathrm{p}<.005, \mathrm{t}=2.700)$. Bu bulgu, Türk kültüründe ortak değerlerin, tanıdıklar arasında iş yapılması olarak algılandığı şeklinde yorumlanabilir. Özerk benlik kurgusunu, stratejik güven yordamış $(\beta=.180, \mathrm{p}<.025, \mathrm{t}=2.263)$ genelleştirilmiş güven ise yordamamıştır $(\beta=-.111, \mathrm{p}<$ $.092, \mathrm{t}=-1.695)$. Korelasyon tablosu incelendiğinde özerk benlik ve genelleştirilmiş güven arasında .14' lük korelasyon bulunmuştur ancak değerler negatif yöndedir. Buradan hareketle genelleştirilmiş güven artıkça özerk benlik kurgusunun düştüğü yorumu yapılabilir. Bu bulgular alanyazın ile ters yönde olup örtüşmemektedir. Genelleştirilmiş güven ve kurumsal güven bireyci toplumların özelliğidir (Allik ve Realo, 2004; Ulsaner, 2002, 2004). Türk kültüründe özerk benlik kurgusuna sahip bireylerin, tanımadığı insanlara ve kurumlara güvenmediği görülmektedir. Bu bulgu, Türk toplumunda sosyal sermayenin düşüklük olduğu ya da sosyal sermayenin bireyci kültüre herhangi bir katkı sağlamadığı şeklinde yorumlanabilir.

Kadınlarda ilişkisel benlik kurgusunu, ortak değerler $(\beta=.242, \mathrm{p}<.016, \mathrm{t}=2.432)$ açıklamaktadır. Bunun yanı sıra genelleştirilmiş güven ve kurumsal güven, ilişkisel benlik kurgusunu yordamamıştır. Araştırmadaki ilginç bulgu, ilişkisel benlik kurgusunu kadınlarda stratejik güvenin yordamamış olmasıdır $(\beta=.130, \mathrm{p}<.188, \mathrm{t}=1.321)$. Alanyazın incelendiğinde stratejik güven toplulukçu kültürlerde yaygındır (Allik ve Realo, 2004; Ulsaner, 2002, 2004). Toplulukçu kültürlerde, kendini toplulukçu hisseden ilişkisel benlik kurgusuna sahip kadınlarda tanıdıklarına güven, bu benlik kurgusunu yordamamıştır. Bu durum kadınların, Türkiye'de benlik biçimlerinden bağımsız olarak, tanıdıklarına ya da yakınlarına bile güvenmediklerine 
işaret etmektedir. Son zamanlarda kadınlara yönelik artan şiddet ve cinsel saldırılar, bu bulgunun nedeni olarak düşünülebilir. Kadınlarda ilişkisel benlik kurgusunu ortak değerler yordamıştır, bu durum da kadınların ortak değerleri yakın hissettikleri kişilere yönelik algıladığı şeklinde yorumlanabilir. Erkeklerde stratejik güven, ilişkisel benlik kurgusunu yordamıştır ( ( $=.296, \mathrm{p}<.005, \mathrm{t}=2.308)$, genelleştirilmiş güven de ilişkisel benliği yordamaktadır $(\beta=-.223, \mathrm{p}$ $<.005, \mathrm{t}=-2.034)$ ancak değerler negatif yöndedir ve bu bulgudan hareketle genelleştirilmiş güven artıkça ilişkisel benlik kurgusunun azaldığı yorumuna ulaşılabilir. Kurumsal güven ve ortak değerler, ilişkisel benlik kurgusunu yordamamıştır. Bu bulgular alanyazında yer alan toplulukçu kültürlerde sosyal sermayenin düşüklüğü şeklindeki değerlerdirmelerle paraleldir. Türk kültüründe erkeklerde ilişkisel benlik ve sosyal sermaye beklendiği gibi ters ilişkilidir, ilişkisel benlik artıkça sosyal sermayenin düşmesi durumu söz konusudur.

Kadınlarda stratejik güven, genelleştirilmiş güven, kurumsal güven ve ortak değerler; özerk benlik kurgusunu yordamıştır $\left(\mathrm{R}=0,262, \mathrm{R}^{2}=0,069, \mathrm{~F}=2.860, \mathrm{P}<0.05\right)$. Ancak açıklanan varyans, çok düşüktür (\%7) ve $\beta$ değerleri incelendiğinde tek başına anlamlı olarak hiçbir değişkeni yordamamaktadır. Değişkenler birlikte varyansın \% 7 sini açıklamakta ancak tek başına ele alındıklarında özerk benlik kurgusuna ilişkin ortalamalar arası varyansı açıklamamaktadırlar. Bu bulgu, kendini özerk hisseden kadınlarda sosyal sermayenin düşük olduğuna işaret etmektedir. Ayrıca bulgu, Putnam'ın, Amerikan toplumda sosyal sermayedeki düşüşün nedenini kadınların sosyal sermaye düzeylerinin düşmesi ile açıklaması, Türkiye'deki bulgunun da bu durumla paralel olduğuna işaret etmektedir. Erkeklerde özerk benlik kurgusunu, ortak değerler yordamış $(B=.286, \mathrm{p}<.033, \mathrm{t}=2.175)$; stratejik güven, genelleştirilmiş güven ve kurumsal güven ise yordamamıştır. Bulgu, Türk toplumunda sosyal sermaye olgusuyla bireycilik arasında ilişki olmadığı ya da Türk toplumunda genel olarak sosyal sermaye olgusunun düşük olduğu yönünde açıklanabilir.

Türk toplumunda genelleştirilmiş güvenin düşüklüğünün nedenleri araştırılmalıdır. Araştırmaya genel olarak bakıldığında, benlik biçimlerinden ve cinsiyetten bağımsız olarak güven düşüktür. Ortak değerler, her iki benlik kurgusunu da yordamaktadır. Bu bulgular, tanıdık ve tanımadık kişiler ile iş yapmanın, Türk kültüründe fark algılanıyor olabileceğine dair bir yorumu gündeme getirmektedir. Bu boyutun incelenmesi gerekmektedir. 


\section{KAYNAKÇA}

Allik J., Realo A. (2004). Individualism-Collectivism and Social Capital, Journal of Cross-Cultural Psychology, 35 (1), (29-49).

Bourdieu, P. (1986). The Forms of Capital. (Eds. John,G. Richarson) Handsbook of Theoery and Research for the Sociology, Greenwood Press. New York, (231-310).

Coleman, J. (1988). Social Capital in The Creation of Human Capital. American Jurnal of Socilogy. 94 (9). (95-120).

Erdoğan, E. (2005), Türk gençliği ve siyasal katılım boyutları.

http://www.ari.org.tr/index.php?option=com_frontpage\&Itemid=1 ( 05.04.2010 da ulaş1ld1).

Field, J. (2006). Sosyal Sermaye. (Çev: Bahar Bilgen ve Bayram Şen) İstanbul Bilgi üniversitesi Yayınları.(Eserin orijinali 2003 yılında yayınland1).

Fukuyama, F. (1998). Güven, Sosyal Erdemler ve Refahın Yaratılması. T. İş Bankası Yayınları: İstanbul.

Markus, H. R. ve Kitayama (1991). Cultural variation in the self-concept (18-48). Multidisciplinary perspectives on the self, (18-48).

Putnam, R. (1996). Tuning In, Tuning Out: The Strange Disappearance of Social Capital in America. Political Science and Politics, 28 (4), (664-683).

Singelis, T. M . (1994). The measurement of independent and interdependent self-construals. Personality and Social Psychology Bulletin, 20, (580-591).

Singelis, T. M., Brown, W. J. (1995). Culture, self, and collectivist communication: Linking culture to individual behavior, Human Communication Research, 21, (354-389).

Uçar, E. M. (2011). Üniversite Öğrencileri ve Üniversiteden Mezun Olan Bireylerin Sosyal Sermaye Düzeylerinin Benlik Biçimleri ve Çeşitti Değişkenler Açısından İncelenmesi. Yayınlanmamış Doktora Tezi, Ankara Üniversitesi Eğitim Bilimleri Enstitüsü: Ankara.

Uslaner, E. M. (2002). The Moral Foundations of Trust. Cambridge University Press: New York.

Uslaner, E. M. (2004). Trust as a Moral Value. Handbook of Social Capital. (Eds.Dario. Castiglione, John, Wan Deth, G. Wolleb) Oxford University Press. (311-398). 


\section{Summary}

Social capital is a result of human relations based on trust and is an immaterial kind of capital. People, through establishing good relationships and maintaining them, can reach goals that would be impossible or too difficult to do by themselves. Working together provides job opportunities, possibilities and a network of communication that could inform them of new relationships. Since they provide sources these communication networks could be regarded as a sort of capital. But to know people and to be in touch with them is not enough for the emergence of a social capital. To feel belonged to the people that you know to trust these people, and to believe that you are sharing common values with these people are necessary for the social capital. Because of this pattern, social capital consists of trust, common values and the emotions of groups belongingness created by social networks. Trust is the most important component of social capital. This dimension of social capital is divided into three in itself: Strategic trust, generalized trust, and institutionalized trust. Strategic trust is the trust between two people who know each other. Generalized trust is the trust relationship between people who don't know each other. When people relate to a person that they don't know, they must believe that this person will not deceive or harm them. Trust in institutions are strongly related to generalized trust, even so that in order for a person to have generalized trust, one has to have trust in institutions. First of all we trust the state institutions and it becomes easier to trust people who we don't know. Trust enables individuals to get together and connect to each other through communication networks, and even allows them to become as a group. Common values are emerged within these networks, which makes individuals feel like they belong to a group. These values are mutual assistance with the group members, organized work and following the group. There is a claim that social capital valid fact in the individualistic western cultures.

In the focus of individualism and collectivism, there is the distinction that individuals define themselves as part of a group or as an independent individual from the group. According to this, communitarians define themselves as part of the group; there is an independent self concept that separates individualist individuals from the group. It is possible to differentiate cultures from two opposite poles as individualist and collectivist. But the individual, who is a part of the collectivist culture, may feel independent from the group and behave in that direction or an individual who overtaken in an individualist culture can act in such a way that he feels communal. Therefore social and cultural psychology proposes autonomous self or independent self frameworks. To put it another way, self construal relate to the individual's feeling autonomous or relational. In cross cultural and social psychology self is defined as dependent and interdependent which explain effect of culture to self. In this approach dependenceinterdependence are how individuals feel and behave regardless individuals live in which society and part of society. Within this context cultural and social psychology point of view use dependence-interdependence self rather than individualism-collectivism. The aim of this study is to examine whether; strategic trust, generalized trust, institutional trust and common values, are predict autonomous, relatedness self or not at women and men.

Method: The research group consisted of 240 (66.7\% female, $33.3 \%$ male) university students. To collect personal data form was used to obtain data on demographical features of the participants such as age and gender. Self-Construal Scale (Singelis, 1994), Strategically Trust Scale, General Trust Scale, Institutional Trust Scale and Common Values Scale (Uçar, 2011) were used. In the study to analyses the data, the multiple regression model which includes the effects of these variables on the self-construal's of social capital, was developed and tested. 
Results: Firstly regression analyzed showed that strategic trust, generalized trust, corporate trust and common values significantly predict relatedness self construal $\left(R=0,384, R^{2}=0,147\right.$, $\mathrm{F}=14,806, \mathrm{P}<0.05)$. When the $\beta$ values in the regression analysis are examined, the strategic trust $(\beta=.206, p<.005, t=2.663)$ and common values $(\beta=.212, p<.005, t=2.700)$ explained of $21 \%$ variance totally in relatedness self construal. On the other hand generalized trust $(B=-.067$, $\mathrm{p}<.293, \mathrm{t}=1.054)$ and institutional trust $(\beta=.011, \mathrm{p}<.866, \mathrm{t}=.69)$ do not predict relatedness self construal. As a result of regression analysis, strategic trust, generalized trust, institutional trust and common values predict autonomous self-construal $\left(\mathrm{R}=0,320, \mathrm{R}^{2}=0,103, \mathrm{~F}=7,651\right.$, $\mathrm{P}<0.05$ ). When the $\beta$ values in the regression analysis are examined, the strategic trust explained of $18 \%$ variance totally in autonomous self construal $(\beta=.180, \mathrm{p}<.025, \mathrm{t}=2.263)$. Generalized $\operatorname{trust}(\beta=-.111, \mathrm{p}<.092, \mathrm{t}=-1.695)$, institutional trust $(\beta=-.046, \mathrm{p}<.291, \mathrm{t}=-1.058)$ and common values $(\beta=.140, \mathrm{p}<.084, \mathrm{t}=1.736)$ do not predict autonomous self-construal. Multiple regression analysis was performed to examine the relationship between self-construal of women and men, strategic trust, generalized trust, institutional trust and common values. The analys show that strategic trust, generalized trust, institutional trust and common values predict relatedness self construal at women $\left(\mathrm{R}=0,338, \mathrm{R}^{2}=0,114, \mathrm{~F}=4.823, \mathrm{P}<0.05\right)$. And strategic trust, generalized trust, institutional trust and common values explained of $11 \%$ variance totally in relatedness self construal at women. Strategic trust, generalized trust, institutional trust and common values significantly predict relatedness self construal at men $\left(R=0,495, R^{2}=0,245\right.$, $\mathrm{F}=5.938, \mathrm{P}<0.05)$. And strategic trust, generalized trust, institutional trust and common values explained of $25 \%$ variance totally in relatedness self construal at men. When the $\beta$ values in the regression analysis are examined, common values explained of $24 \%$ variance totally in relatedness self construal at women $(B=.242, \mathrm{p}<.005, \mathrm{t}=2.432)$. Strategic $\operatorname{trust}(\beta=.130, \mathrm{p}<$ $.188, \mathrm{t}=1.321)$, generalized trust $(\beta=.017, \mathrm{p}<.836, \mathrm{t}=208)$ and institutional trust $(B=-.009, \mathrm{p}<$ $-.009, \mathrm{t}=-.116)$ do not predict relatedness self construal at women. When $\beta$ values at men are examined, strategic trust explained of $30 \%$ variance totally in relatedness self construal ( $\beta$ $=.298, \mathrm{p}<.024, \mathrm{t}=2.308)$. Generalized trust explained of $21 \%$ variance totally in relatedness self construal at men $(\beta=-.213, \mathrm{p}<.046, \mathrm{t}=-2.034)$ but direction is negative, its means when generalized trust increase relatedness self construal is decreased. Institutional trust $(B=-.030, p$ $<.705, \mathrm{t}=.381)$ and common values $(\beta=.193, \mathrm{p}<.194, \mathrm{t}=1.311)$ do not predict relatedness self construal at men. Strategic trust, generalized trust, institutional trust and common values predict self autonomous construal at women $\left(\mathrm{R}=0,258, \mathrm{R}^{2}=0,67, \mathrm{~F}=2.700, \mathrm{P}<0.05\right)$. Strategic trust, generalized trust, institutional trust and common values explained of $7 \%$ variance totally in self autonomous construal at women. Strategic trust, generalized trust, institutional trust and common values predict self autonomous construal at men $\left(\mathrm{R}=0,466, \mathrm{R}^{2}=0,217, \mathrm{~F}=5.072\right.$, $\mathrm{P}<0.05)$. The analys show that strategic trust, generalized trust, institutional trust and common values explained of $22 \%$ variance totally in self autonomous construal at men. When $\beta$ values at women in the regression analysis are examined, strategic $\operatorname{trust}(\beta=-.171, \mathrm{p}<.092, \mathrm{t}=1.696)$, generalized trust $(B=-.154, \mathrm{p}<.066, \mathrm{t}=1.854)$, institutional trust $(B=-.042, \mathrm{p}<.612, \mathrm{t}=-.509)$ and common values $(\beta=-.056, \mathrm{p}<.501, \mathrm{t}=.-.675)$ do not predict self autonomous construal. This analys shows that $7 \%$ of the variance is explained when these variables are together, but they do not explain the variance between the averages of autonomous self. When the $\beta$ values at men in the regression analysis are examined, common values explained of $29 \%$ variance totally in self autonomous construal $(\beta=.286, \mathrm{p}<.033, \mathrm{t}=2.175)$. And also strategic trust $(\beta=-$ $.221, \mathrm{p}<.096, \mathrm{t}=1.1685)$, generalized trust $(\beta=-.037, \mathrm{p}<.728, \mathrm{t}=-.349)$, institutional trust $(\beta=-$ $.078, \mathrm{p}<.476, \mathrm{t}=-.717$ ) do not predict self autonomous construal at men.

Trust between familiar or intimate relationships is greater in collectivist cultures (Allik ve Realo, 2004; Ulsaner, 2002, 2004). In Turkish society, strategic trust and common values predict relatedness self construal. However generalization trust and institutional trust do not predicts relatedness self construal. This finding can be interpreted that common values in 
Turkish culture are perceived as doing business between acquaintances. In addition, individuals who have autonomous self construal in Turkish culture do not trust the people and institutions they do not know. In conclusion, the study revealed that in Turkish culture, it is seen that individuals who have autonomous self- construal do not trust people and institutions they do not know. When the data in the study is evaluated, it can be interpreted that social capital is low in Turkish society or social capital does not contribute to individualistic culture.

Keywords: Social Capital, Autonomous, Relatedness Self 